\title{
Platelet Parameters and Variations With Age Amongst Elderly Nepalese Presenting in BPKIHS, Dharan Research Project (March 29-April 25)
}

\author{
Indira Ojha*, Seema Oli \\ Department of Pathology, BP Koirala Institute of Health Sciences, Dharan, Nepal
}

Email address:

indiraojha1@yahoo.com (I. Ojha)

${ }^{*}$ Corresponding author

\section{To cite this article:}

Indira Ojha, Seema Oli. Platelet Parameters and Variations With Age Amongst Elderly Nepalese Presenting in BPKIHS, Dharan Research Project (March 29-April 25). Biomedical Sciences. Vol. 5, No. 4, 2019, pp. 67-70. doi: 10.11648/j.bs.20190504.15

Received: June 21, 2019; Accepted: July 18 DD, 2019; Published: November 25, 2019

\begin{abstract}
Platelets are derived from megakaryocytes and help in hemostasis and produce growth factors. Platelet count and MPV are parameters used in various conditions and vary with age and sex. The purpose of this study was to compare platelet count and MPV of healthy young with healthy elderly and calculate normal range of platelet count and to find relationship of platelet count and MPV with age and sex. Prospective study was done on 202 people visiting hematology department of BPKIHS, 100 as cases and 102 as controls, after obtaining ethical clearance. Only the consenting individuals and individual meeting inclusion criteria were included in the study. Blood sample was drawn in EDTA vial and Platelet counts and MPV was measured by 5 part hematology analyzer. Results showed that platelet count is higher in females and young individuals while platelet volume is higher in elderly. Study shows that there is insignificant difference between platelet count and MPV between elderly population and young control. Thus, from this prospective study conducted on 202 people we concluded that there is a rise in MPV with age and decrease in platelet count. However, the difference is insignificant and does not mandate separate reference range for various age groups.
\end{abstract}

Keywords: Platelets, Platelet Count, Mean Platelet Volume

\section{Introduction}

Ageing is decrease in working capacity of different organ system leading to increased chances of dysfunction and disease. Decline in pluripotent cytokines and growth factors result in decrease in haematopoietic stem cells disrupting normal system [1]. Hence, age factor should be considered [2]

Megakaryocytes fragments in the bone marrow to produce platelets which help in hemostasis and produce growth factors. Decrease or increase in their number and function cause platelet disorders [3].

Platelets lack nucleus and circulate at 150,000 to $450,000 / \mathrm{mm}^{3}$. [4]. Platelets are smaller in size and arise from larger megakaryocytes which are polyploidy. Variations in platelet size are determined at the time of synthesis in bone marrow and these differences may cause cardiac problems [5] MPV tells about the size of platelets [6]. And sufficient platelet count is necessary for hemostasis. [7] Thus, platelet count and MPV also help in determining thrombotic potential [8].

Platelet heterogeneity arise at thrombopiesis. Aging is not responsible for decrease in platelet size rather they are independent determinants of platelet function [9].

Studies done on fewer individuals by using manual counting techniques were used to calculate normal platelet counts and these values are used by standard hematology textbook. It is easier to conduct platelet count studies on a large group of individuals with precision because of automatic counting and data processer tools. This research aims at determining the mean platelet counts in males and females of different age groups and finding out if there is any significant variation between age groups

Patients commonly undergo complete blood count.. Previous researches have shown platelet counts to be significantly higher in women $[4,10]$. There is still much to 
know about variations in platelet counts in healthy adults.

\section{Rationale}

BPKIHS is a tertiary care Centre located in eastern region of Nepal. In this study we will investigate about changes in platelet counts and mean platelet volume with increasing age. We will investigate difference in platelet counts and platelet volume with respect to gender. Since there have been no research conducted in the past in Platelet counts and Mean Platelet Volume in elderly in BPKIHS, we want to calculate the suitable range and relationship with aging.

According to research conducted in Nigeria [11], there was significant gender dependent variations in platelet count and mean platelet volume. Moreover, platelet count was found to decrease with age. So, we have chosen this topic:

1. To compare platelet counts and mean platelet volume of healthy controls of age group 20 - 30 years and healthy cases of age group 50 and above

2. To find suitable reference values of platelet counts and mean platelet volume in elderly males and females

\section{Objectives}

\section{Primary objective:}

To compare platelet counts and mean platelet volume of healthy controls of age group $20-30$ years and healthy cases of age group 50 and above.

2. Secondary objectives:

1) To find out suitable values of platelet counts and mean platelet volume in elderly males and females

2) To find out relationship between platelet size and number

\section{Literature Review}

Studies on platelet counts have shown that number of platelets decreases with age so that thrombocytopenia was rare in young people whereas thrombocytosis was common. [12].

Blood cell counts in elderly people above 65 years showed blood cell count to be significantly different for males and females except for basophils. Hence, blood cell count should be gender specific. [13]

Females have higher platelet counts compare to males (261 vs. $237 \times 10^{9} / \mathrm{L}, \mathrm{P}<0.001$ ), and platelet number fell with increasing age, with a decrease from infancy to old age of $35 \%$ in males and about $25 \%$ females. This falling trend common in all investigated populations. Platelet count in population under 15 years was significantly higher compared to the population above 15 years and below 65 years (299 vs $252 \times 10^{9} / \mathrm{L}, \mathrm{P}<0.001$ ), and platelet count in population of 15 64 years was significantly higher when compared to population over 64 years $\left(252\right.$ vs $\left.233 \times 10^{9} / \mathrm{L}, \mathrm{P}<0.001\right)$. Under 15 years of age, variation in platelet count of men and women was not significant ( 298 vs $\left.299 \times 10^{9} / \mathrm{L}, \mathrm{P}=0.690\right)$, but women of age range 15-64 years and over 64 years had significant difference $\left(264\right.$ vs $\left.238 \times 10^{9} / \mathrm{L}, \mathrm{P}<0.001\right)$ and $(245$ vs $\left.220 \times 10^{9} / \mathrm{L}, \mathrm{P}<0.001\right)$ respectively. [12]

The mean platelets count of $218.90 \times 10^{9} / \mathrm{L}$ and $247.8 \times$ $10^{9} / \mathrm{L}$ were determined among men and women blood donors respectively. Statistically insignificant rise in platelet count was noted $(\mathrm{P}=0.01)$. Similar insignificant difference was noted in case of MPV $(\mathrm{P}=0.01)$. This study showed platelet count to be sex specific and gender should be considered while diagnosing thrombocytopenia [14]

Likewise, increased platelet count in females $252.35+/$ $41.25 \times 10(9) / 1$ as compared to men $221.87+/-37.63 \times$ $10(9) / 1(\mathrm{p}=0.0002)$ was noted and statistically insignificant differences were noted in case of MPV by Butkiewicz AM et al. Platelet count is sex variable, being higher in females than males [4].

\section{Materials and Methods}

Study setting: BPKIHS, Dharan Municipality of Sunsari District.

Study group: Elderly men and women of age group 50 and above years visiting Hematology lab of BPKIHS as cases and healthy males and females of age group $20-30$ years as controls.

Sample size: 202

100 cases: 47 Males and 53 Females

102 controls: 29 Males and 73 Females

Sampling frame: people who visited hematology department of BPKIHS

Inclusion Criteria:

Males and females aged 50 and above years. Similarly, young adults aged 20 - 30 years were used as control.

Exclusion Criteria:

Males and females not giving verbal consent.

No history of terminal illness like carcinoma, thalassemia, sickle cell disease, tropical diseases like malaria, dengue, no history of blood loss or blood transfusion in last six months

Data Collection Tools:

Data collection will be carried out at Hematology Department of BPKIHS. Face to face interview will be taken to fill the semi-structured questionnaire.

Platelet counts and Mean Platelet Volume was measured by 5 part differential hematology analyzer which measured 22 parameters in total. $2 \mathrm{ml}$ of venous blood from each case and control was collected into sodium citrate vials. The analyzer reports within 1 minute and can keep back record up to 1000 . This method is faster than manual method.

Ethical clearance:

Ethical clearance was obtained from Institutional Ethical Review Board of BPKIHS.

Statistical analysis:

All interviewed questionnaire was indexed and kept on file. Database was entered in Microsoft Excel 2007 and converted into SPSS $11.5 \mathrm{v}$ for statistical analysis. For descriptive statistics mean and Standard deviation will be calculated along with it tabular presentation will be made. For inferential statistics, $\chi 2$, $\mathrm{z}$ or $\mathrm{U}$ test will be applied to find 
out the significant difference between platelet count in elderly and young at $95 \%$ confidence interval where $\mathrm{p}=$ 0.05 .

RESEARCH PROCESS (thorough and clear description of all data gathering processes that will take place)

1. The study requires patients' participation in a face to face interview to discuss questions related to research.

2. They need to show us their OPD card and lab investigation reports.

3. They have the total will to leave the interview, and it's their choice to voluntarily take part in the interview.

\section{Results}

The mean platelet count was 200.36X 109/L with 94.695 S. D. in healthy elderly males and 207.13 x109/L with 68.965 S. D. in females. There was an insignificant decrease $(\mathrm{P}>0.05)$ in the mean platelet count in the healthy aged males and females when compared with $190.67 X 109 / \mathrm{L}$ with S. D $60.774 \times 109 / \mathrm{L}$ in males and $227.93 \mathrm{X} 109 / \mathrm{L}$ with $\mathrm{S}$. D.66.371 X 109/L in female healthy young adult control. Mean platelet count in young adult control was higher but the rise was insignificant $(\mathrm{P}>0.05)$ (Table 3$)$.

MPV in the elderly men was $10.31 \mathrm{fl}$ with S. D. 1.49 and females was $10.72 \mathrm{fl}$ with S. D. $1.769 \mathrm{fl}$ and and in young controls was $10.93 \mathrm{fl}$ with S. D $1.80 \mathrm{fl}$ in females and $10.58 \mathrm{fl}$ with S. D $1.86 \mathrm{fl}$ respectively. The fall in mean platelet volume in the healthy aged population was statistically insignificant ( $\mathrm{P}>0.05$ ) compared to that of the young adult population (Table 3). Inverse correlation between mean platelet count and mean platelet volume $(\mathrm{r}=0.001)$ was noted.

Table 1. Platelet number and size in elderly.

\begin{tabular}{lll}
\hline Parameters & Males $(\mathbf{n}=\mathbf{4 7})$ & Females $(\mathbf{n}=\mathbf{5 3})$ \\
\hline Platelet counts & $200.36 \times 109 / \mathrm{L}$ & $207.13109 / \mathrm{L}$ \\
MPV & $10.31 \mathrm{fl}$ & $10.72 \mathrm{fl}$ \\
\hline
\end{tabular}

Table 2. Platelet number and size in controls.

\begin{tabular}{lll}
\hline Parameters & Males $(\mathbf{n}=\mathbf{2 7})$ & Females $(\mathbf{n}=\mathbf{7 3})$ \\
\hline $\begin{array}{l}\text { Platelet counts( X 109 } \\
\text { / ) }\end{array}$ & 190.67 & 227.93 \\
MPV in fl & 10.58 & 10.93 \\
\hline
\end{tabular}

Table 3. Platelet count and MPV in Males/Females and cases/controls.

\begin{tabular}{llll}
\hline Sex & Platelet Count & MPV & Number \\
\hline Male & 211.43 & 10.697030 & 126 \\
Female & 198.58 & 10.451316 & 76 \\
Parameter & Platelet Count & MPV & Number \\
Controls & 218.76 & 10.86 & 102 \\
Cases & 203.95 & 10.53 & 76 \\
\hline
\end{tabular}

\section{Discussion}

Results from this study showed that more platelets are found in females and young individuals whereas lesser in elderly and males. Sex specific variation in platelet count was shown amongst the Algerians [15]. [4] observed higher count in females.
Decline in platelet count in healthy elderly males and females noted in this study may be due to hookworm infestation which is common in Nepal. Likewise, increased fatty tissue replacement of bone marrow, impaired cytokine production in the aged population, low intake iron, protein, vitamins and folic acid. Malaria, dengue and malignancy can result in decline in platelet count but only healthy population was taken into account in this study.

Large platelets produced in response to decrease platelet counts were found to be less reactive. [9]. Mean platelet Volume depends on thrombopietic conditions.

Inverse correlation between platelet count and MPV was observed [11].

But unlike their findings [12], the platelet count in male control is less than those of elderly males and platelet count in the age range 20-30 years was insignificantly higher when compared to subjects over 49 years. Women had more platelets in the age range $15-64$ years $\left(264\right.$ vs $238 \times 10^{9} / \mathrm{L}$, $\mathrm{P}<0.001)$ and over 64 years $\left(245\right.$ vs $\left.220 \times 10^{9} / \mathrm{L}, \mathrm{P}<0.001\right)$ [12]). We found similar increase but the increase was insignificant.

With the advent of technology and awareness, more and more blood counts are being done, it is crucial to avoid sending unnecessary investigations for age and sex related variation in platelet count. Further studies are to be conducted among a large healthy population for accurate reference values for male and female. On the contrary to the study conducted amongst Nigerians [11], this study suggests that there is an insignificant variation in platelet count and mean platelet volume calculated between the healthy aged population and the young adult control $(\mathrm{P}>$ 0.05). Therefore separate values for platelet count and mean platelet volume for the elderly is not necessary. Hence, the same reference values $150 \times 109 / 1$ and 6.5 to 12.0fl. Moreover, the increase in platelet count in females was insignificant on the contrary to findings of [13] but agrees with findings of [14]. So, normal ranges for haematological indices need not be sex-specific.

\section{Conclusion}

Thus, from this prospective study conducted on 202 people we concluded that there is a rise in MPV with age and decrease in platelet count. However, the difference is insignificant and does not mandate separate reference range for various age groups.

\section{References}

[1] Mariza, D. S., Claria, H. A., Schivanke, M. B., Clarice L., Irana, M. C. (2007). Haematological and nutritional parameters in apparently healthy elderly individuals. Revista Brasleira Hematologia e Hemoterapia 29 (2): 10.

[2] Madimir, M. D. (1981). Diseases of Ageing. John Wright PSG Inc. London. Giles, C. (2008). Platelet count and mean platelet volume. British Journal of Haematology, 48 (1): 31-37. 
[3] Bath, P. M., Butterworth R. J. (1996). Platelet size: measurement, physiology and vascular disease. Blood Coagulation and Fibrinolysis, Vol. 7 (2); 152-161.

[4] Butkiewicz AM, Kemona H, Dymicka-Piekarska V, Matowicka-Karna J, Radziwon P, Lipska A (2006): Platelet count, mean platelet volume and thrombopoietic indices in healthy women and men. Thrombosis Res, 118: 199-204.

[5] Bernd, van der Loo, John, F. M. (1999). A Role for Changes in Platelet Production in the Cause of Acute Coronary Syndromes. Arteriosclerosis, Thrombosis, and Vascular Biology, 19: 672-679.

[6] Wu, Yang Yang et al (2019) Mean platelet volume/platelet count ratio in colorectal cancer: a retrospective clinical study. BMC Cancer 19: 314.

[7] Aleksandra Korniluk et al (2019) Mean Platelet Volume (MPV): New Perspectives for an Old Marker in the Course and Prognosis of Inflammatory Conditions. Hindawi Mediators of Inflammation, Article ID 9213074, 14 pages.

[8] BHATTA, Sushama et al. (2019) Mean Platelet Volume and Platelet Count in Patients with Type 2 Diabetes Mellitus and Impaired Fasting Glucose. Journal of Nepal Health Research Council, [S. 1.], v. 16, n. 41, p. 392-395. ISSN 1999-6217.

[9] Martin, J. F., Plumb, J., Kilbey, R. S., Kishk, Y. T. (1983). Changes in volume and density of platelets in myocardial infarction. British Medical Journal, 287: 456-459.
[10] Kemona H, Prokopanicz J, Wolosanicz N (1977): The count of blood platelets and sex in humans. Cell Mol Life Sci, 34: 257.

[11] Toryila, J. E., Amadi, K., \& Adelaiye, A. B (2009). Platelet Counts And Mean Platelet Volume Amongst Elderly Nigerians Science World Journal 4 (1): 1597-6343.

[12] Ginevra Biino, Carlo L. Balduini, Laura Casula, Piergiorgio Cavallo, Simona Vaccargiu, Debora Parracciani, Donatella Serra, Laura Portas, Federico Murgia, and Mario Pirastu(2011): Analysis of 12,517 inhabitants of a Sardinian geographic isolate reveals that predispositions to thrombocytopenia and thrombocytosis are inherited traits, Haematologica.

[13] Rowan Mcllhagger1, Alan J Gow2,3, Caroline E Brett3, Janie Corley 3, Michelle Taylor3, Ian J Deary2,3 and John M Starr (2010): Differences in the haematological profile of healthy 70 year old men and women: normal ranges with confirmatory factor analysis, BMC Blood Disorders, 10: 4

[14] Okeke P. U. (2012): Platelet Count and Indices of Mean Platelet Volume, Platelet Distribution Width and Platelet Large Cell Ratio - Is there any Sex Difference?; 17, 978-3656-16529-3.

[15] Brahimi, S., Arabi, A., Touhami, H., Seghier, F., Kubisz, P., Cronberg, S. (1984). Platelet count and mean platelet volume in an Angerian population indicating a new prevalence of mediterran macrothrombocytopenia. Human Hered., 34: 396398. 